\title{
Consumo, parâmetros ruminais e concentração de uréia plasmática em novilhos alimentados com diferentes níveis de torta de girassol em substituição ao farelo de algodão ${ }^{1}$
}

\author{
Intake, ruminal parameters and plasmatic urea concentration \\ in beef cattle fed diets with different levels of sunflower cake in \\ substitution to the cotton meal
}

\author{
Adriana Rosa Domingues²; Leandro das Dores Ferreira da Silva ${ }^{3 *}$; \\ Edson Luis de Azambuja Ribeiro ${ }^{3}$; Valdecir de Souza Castro ${ }^{4}$; \\ Marco Aurélio Alves de Freitas Barbosa ${ }^{3}$; Rinaldo Masato Mori ${ }^{4}$; \\ Mariana Torres Licursi Vieira5; Janaína Aparecida de Oliveira da Silva ${ }^{5}$
}

\section{Resumo}

O objetivo deste trabalho foi avaliar os efeitos da torta de girassol (TG), em cinco níveis de substituição ao farelo de algodão, sobre o consumo de matéria seca (CMS), pH e concentração de nitrogênio amoniacal $\left(\mathrm{N}-\mathrm{NH}_{3}\right)$ no líquido ruminal e de uréia plasmática em novilhos de corte. As rações foram isoprotéicas $(13,0 \% \mathrm{~PB})$ e isoenergéticas ( $72,0 \% \mathrm{NDT})$. A silagem de cana-de-açúcar in natura, como volumoso, foi utilizada na proporção de $40 \%$ da MS fornecida. Foram utilizados cinco animais fistulados no rúmen, machos, castrados, $1 / 2$ sangue Simental x Nelore, pesando em média $380 \mathrm{~kg}$ e 24 meses. Os tratamentos foram: $0 \%$ (TG0); 25\% (TG25); 50\% (TG50); 75\% (TG75) e 100\% (TG100) de torta de girassol (base na MS) em substituição ao farelo de algodão. O experimento foi conduzido em quadrado latino 5 x 5 , sendo 5 animais e 5 períodos. Cada período experimental teve duração de 15 dias. Os animais alimentados com a ração TG0 ingeriram mais $(\mathrm{P}<0,05)$ matéria seca $(\mathrm{MS})$, em $\mathrm{kg}$ por dia, do que quando receberam rações contendo torta de girassol. No entanto, não foram observadas diferenças para os valores de $\mathrm{pH}$ e $\mathrm{N}_{-} \mathrm{NH}_{3}$ do líquido ruminal e uréia plasmática. Conclui-se que a torta de girassol pode ser usada em substituição ao farelo de algodão em rações suplementares visando médias taxas de ganho diário, pois esta em altos níveis de substituições do farelo de algodão acarretou menor ingestão de MS.

Palavras-chave: Cana-de-açúcar, nitrogênio amoniacal, novilho, $\mathrm{pH}$

\footnotetext{
Abstract

The objective of this study was to assess the effects of five substitution levels of cotton meal by sunflower cake in the concentrate ration, on dry matter intake (DMI), $\mathrm{pH}$ and ammonia nitrogen $\left(\mathrm{N}-\mathrm{NH}_{3}\right)$ in the rumen liquid and plasmatic urea in beef steers. The diets were isoprotein $(13.0 \% \mathrm{CP})$ and isoenergetic $(72.0 \% \mathrm{TDN})$. In natura sugarcane silage was the only ronghage $(40 \% \mathrm{DM})$. Five $1 / 2$ Simental $\mathrm{x}$ Nelore, castrated males were used, with average weight of $380 \mathrm{~kg}$ and 24 months old, all fistulated in the rumen.

${ }^{1}$ Parte da Dissertação de Mestrado do primeiro autor, Universidade Estadual de Londrina.

${ }^{2}$ Mestre em Ciência Animal/Produção Animal, Universidade Estadual de Londrina. E-mail: leandro@uel.br

${ }^{3}$ Profs. Drs. Departamento de Zootecnia, Centro de Ciências Agrárias, Universidade Estadual de Londrina, CCA/UEL- Cx. Postal 6001, CEP: 86051-990, Londrina-PR.E-mail: leandro@uel.br; elar@uel.br; maafbarbosa@uel.br

${ }^{4}$ Pós-graduando em Ciência Animal

${ }^{5}$ Graduanda em Zootecnia, Iniciação Científica, Universidade Estadual de Londrina. E-mail: leandro@uel.br

* Autor para correspondência
} 
The treatments were: $0 \%$ sunflower cake (TG0); 25\% sunflower cake (TG25); 50\% sunflower cake (TG50); 75\% sunflower cake (TG75); and 100\% sunflower cake (TG100), based on DM, substituting cotton meal (FA). The experiment was carried out in a 5x5 Latin square experimental design, with five animals and five periods. Each experimental period lasted 15 days. The dry matter intake (DMI) presented significant difference $(\mathrm{P}<0.05)$, showing that substituting cotton meal by sunflower cake resulted in lower DM intake, but this substitution did not $(\mathrm{P}>0.05)$ alter the $\mathrm{pH}$ and $\mathrm{N}-\mathrm{NH}_{3}$ values of the rumen liquid and plasmatic urea values. It was concluded that sunflower cake can be used in substitution to the cotton meal when mean daily gains are expected, since in high levels of substitution it caused a decrease in DMI.

Key words: Sugar cane, ammonia nitrogen, steer, $\mathrm{pH}$

\section{Introdução}

O sucesso dos ruminantes no processo evolutivo tem sido atribuído à existência de uma relação simbiótica do hospedeiro com a microbiota ruminal. O animal, através da ingestão do alimento, fornece ao rúmen os nutrientes necessários para o crescimento dos microrganismos que, de sua parte, suprem o animal com ácidos graxos voláteis resultantes da fermentação e proteína microbiana (KOZLOSKI, 2002).

O uso de fontes protéicas verdadeiras pode otimizar o metabolismo da microbiota ruminal através da melhoria nos processos fermentativos, sobretudo das bactérias, com conseqüentes reduções nos custos de produção. Segundo o NRC (1996), a proteína sintetizada pelos microrganismos ruminais pode atender até $100 \%$ das exigências de bovinos de corte. Além disso, a suplementação alimentar de bovinos através de suplementos concentrados pode aumentar o consumo total de nutrientes, fornecendo não só aqueles necessários ao organismo do animal como também, para os microrganismos presentes no rúmen.

A ingestão de matéria seca é um dos mais importantes parâmetros na avaliação dos alimentos, pois além de estar relacionada ao enchimento do rúmen, é importante meio do fornecimento das quantidades necessárias de nutrientes requeridos pelos ruminantes. Nesse sentido, o NRC (1996) recomendou valores de consumo médio de matéria seca de $2,5 \%$ do peso vivo para bovinos de corte.
Para maximizar o aproveitamento da fibra pelos microrganismos é importante a avaliação do nitrogênio disponível para síntese microbiana. Devese atentar, ainda, para que o nível deste elemento não seja excessivamente elevado, pois isto pode levar à intoxicação do animal ou elevar o gasto energético para excreção do excedente em forma de uréia.

$\mathrm{O} \mathrm{pH}$ do líquido ruminal varia entre 6 e 7 para atividade proteolítica do rúmen. Porém, a atividade máxima dos microrganismos ocorre em $\mathrm{pH}$ próximo de 6,5 para a maioria dos microrganismos. A manutenção destas condições favoráveis é fundamental para as atividades dos microrganismos celulolíticos (COELHO DA SILVA; LEÃO, 1979). Cerca de 60 a 90\% do nitrogênio consumido pelos animais é convertido em amônia pela atividade bacteriana ruminal e deste, 50 a $70 \%$ pode ser derivado da amônia (KOZLOSKI, 2002).

A concentração de amônia pode ser usada como indicador da eficiência de sua utilização no rúmen. Altas concentrações de amônia ruminal resultam em maior absorção líquida de nitrogênio amoniacal $\left(\mathrm{N}-\mathrm{NH}_{3}\right)$ pelas paredes do rúmen, conversão em uréia e conseqüentes perdas através da excreção urinária (ASSIS et al., 2004).

Este trabalho foi conduzido com objetivo de determinar o consumo de matéria seca (CMS), o $\mathrm{pH}$ e o $\mathrm{N}_{-} \mathrm{NH}_{3}$ no líquido ruminal, bem como a concentração de uréia plasmática no sangue de bovinos de corte alimentado com rações compostas com torta de girassol substituindo o farelo de algodão em $0 \%, 25 \%, 50 \%, 75 \%$ e $100 \%$. 


\section{Material e Métodos}

O experimento foi conduzido na Unidade Experimental com Bovinos de Corte (UNEB) e as análises químicas realizadas no Laboratório de Nutrição Animal do Departamento de Zootecnia da Universidade Estadual de Londrina.

Foram utilizados cinco bovinos machos $1 / 2$ sangue Simental x Nelore, castrados, pesando em média $380 \mathrm{~kg}$ e com 24 meses de idade e canulados no rúmen.

Os animais foram alojados durante todo período experimental em baias cobertas, providas de comedouros e bebedouros individuais. O experimento teve duração de 75 dias divididos em cinco períodos consecutivos.

Os primeiros dez dias de cada período foram usados para adaptação dos animais às condições experimentais e os cinco dias seguintes para colheitas de dados relacionados ao consumo de alimentos, para amostragens do líquido ruminal e do sangue para a determinação do $\mathrm{pH}$ e das concentrações de $\mathrm{N}-\mathrm{NH}_{3}$ e uréia.
Foram estudadas cinco rações isoenergéticas ( $72 \%$ de NDT) e isoprotéicas (13\% PB) de acordo com os requerimentos sugeridos pelo NRC (1996) para bovinos de corte visando ganho de peso diário de $1,1 \mathrm{~kg}$.

Os tratamentos estudados basearam-se na substituição do farelo de algodão pela torta de girassol: (TG0) farelo de algodão (100\%); (TG25) farelo de algodão $(75 \%)+$ torta de girassol $(25 \%)$; (TG50) farelo de algodão (50\%) + torta de girassol (50\%); (TG75) farelo de algodão (25\%) + torta de girassol (75\%) e (TG100) torta de girassol (100\%). Os animais foram arraçoados às 8:00 e às 17:00 h, diariamente. $\mathrm{O}$ total fornecido para cada animal foi padronizado de forma que houvesse sobra diária de $10 \%$ da MS fornecida. A ração fornecida e as sobras foram pesadas diariamente para calcular o CMS pelos animais.

As composições percentuais das rações experimentais estão apresentadas na Tabela 1.

Tabela 1. Composição das rações experimentais em porcentagem da matéria seca (\% MS).

\begin{tabular}{lccccc}
\hline \multirow{2}{*}{\multicolumn{1}{c}{ Alimentos }} & \multicolumn{5}{c}{ Níveis de substituição do farelo de algodão pela torta de girassol ${ }^{\mathbf{1}}$} \\
\cline { 2 - 6 } & TG0 & TG25 & TG50 & TG75 & TG100 \\
\hline Silagem de cana-de-açúcar & 40,00 & 40,00 & 40,00 & 40,00 & 40,00 \\
Torta de girassol & - & 3,95 & 12,30 & 25,90 & 41,15 \\
Farelo algodão & 17,55 & 15,81 & 12,30 & 6,48 & - \\
Milho grão & 41,55 & 39,34 & 34,50 & 26,72 & 17,95 \\
Mineral & 0,90 & 0,90 & 0,90 & 0,90 & 0,90 \\
\hline
\end{tabular}

${ }^{1}$-100\% Farelo algodão (TG0); 75\% Farelo algodão + 25\% Torta girassol TG25; 50\% Farelo algodão + 50\% Torta girassol (TG50); 25\% Farelo algodão + 75\% Torta girassol (TG75); 100\% Torta girassol (TG100).

As dietas individualizadas foram compostas com $60 \%$ de concentrado e $40 \%$ de silagem de cana-deaçúcar. Os teores de matéria seca e de proteína bruta dos alimentos utilizados neste estudo, foram obtidos através de análises realizadas no LANA segundo metodologias citadas por Silva e Queiroz (2002). As quantidades de proteína não-degradável no rúmen
(PNDR) e de proteína degradável no rúmen (PDR) foram obtidas através de testes de degradabilidade in situ, em bovinos, considerando uma taxa de passagem a 5\%/hora e os teores de NDT estimados através de equações citadas por McDowell et al. (1974). 
Tabela 2. Teores de Matéria seca (MS), Proteína bruta (PB), Proteína não-degradável no rúmen (PNDR), Proteína degradável no rúmen (PDR) e Nutrientes digestíveis totais (NDT) dos alimentos utilizados nas rações experimentais.

\begin{tabular}{lccccc}
\hline Alimentos & MS\% & PB\% & PNDR\% & PDR\% & NDT\% \\
\hline Silagem de cana-de-açúcar & 21,26 & 4,05 & 1,76 & 2,29 & 60,73 \\
Torta de girassol & 90,56 & 23,50 & 5,59 & 17,91 & 79,70 \\
Farelo de algodão & 89,92 & 42,22 & 22,17 & 20,05 & 74,75 \\
Milho grão & 91,23 & 9,56 & 4,08 & 5,48 & 83,25 \\
\hline
\end{tabular}

Foram colhidos $100 \mathrm{~mL}$ de líquido ruminal, via cânula, no $15^{\circ}$ dia de cada período com intervalo de duas horas entre cada colheita. Os horários de colheitas obedeceram ao fornecimento da ração, sendo considerada a hora zero, correspondente à colheita antecedente à alimentação dos animais, e 2, 4, 6 e 8 horas após o fornecimento da ração aos animais, pela manhã.
As amostras de líquido ruminal foram colhidas em quatro pontos diferentes do rúmen, sendo filtradas em duas camadas de gaze para posteriores determinações do $\mathrm{pH}$ e da concentração de $\mathrm{N}-\mathrm{NH}_{3}$.

$\mathrm{O} \mathrm{pH}$ foi determinado imediatamente após a filtragem do líquido com o uso de um potenciômetro digital.

Tabela 3. Teores de Matéria seca (MS) Proteína bruta (PB), Proteína não-degradável no rúmen (PNDR), Proteína degradável no rúmen (PDR) e Nutrientes digestíveis totais (NDT) das rações experimentais.

\begin{tabular}{lccccc}
\hline \multirow{2}{*}{ Nutrientes } & \multicolumn{5}{c}{ Níveis de substituição do farelo de algodão pela torta de girassol } \\
\cline { 2 - 5 } & TG0 & TG25 & TG50 & TG75 & TG100 $^{\mathbf{1}}$ \\
\hline MS\% & 100,00 & 100,00 & 100,00 & 100,00 & 100,00 \\
PB\% & 13,00 & 12,98 & 13,00 & 13,00 & 13,01 \\
PNDR\% & 6,29 & 6,03 & 5,52 & 4,68 & 3,74 \\
PDR\% & 6,71 & 6,95 & 7,48 & 8,32 & 9,27 \\
NDT\% & 72,00 & 72,01 & 72,01 & 72,02 & 72,03 \\
\hline
\end{tabular}

${ }^{1}-100 \%$ Farelo algodão (TG0); 75\% Farelo algodão + 25\% Torta girassol TG25; 50\% Farelo algodão + 50\% Torta girassol (TG50); $25 \%$ Farelo algodão $+75 \%$ Torta girassol (TG75); 100\% Torta girassol (TG100).

Alíquotas de $50 \mathrm{~mL}$ de cada amostra de líquido ruminal foram acidificadas com a adição de $1 \mathrm{~mL}$ de ácido sulfúrico $1: 1$, condicionadas em frascos plásticos e congeladas a $-20{ }^{\circ} \mathrm{C}$, para posteriores determinações dos teores de $\mathrm{N}-\mathrm{NH}_{3}$.

Após degelo das amostras, as concentrações de $\mathrm{N}-\mathrm{NH}_{3}$ foram determinadas pela destilação de $2 \mathrm{~mL}$ de cada amostra com adição de $5 \mathrm{~mL}$ de $\mathrm{KOH} 2 \mathrm{~N}$ em aparelho tipo Kjedhal. O destilado foi recebido em $10 \mathrm{~mL}$ de $\mathrm{H}_{3} \mathrm{BO}_{3} 2 \%$ até volume final de $50 \mathrm{~mL}$, seguido pela titulação com HCL $0,005 \mathrm{~N}$, segundo a técnica de Fenner (1965) adaptada por Vieira (1980).
As amostras de sangue foram colhidas por punção da veia jugular no $15^{\circ}$ dia de cada período com intervalo de duas horas entre cada colheita. Os horários de colheita obedeceram ao fornecimento da ração, sendo considerado o tempo zero, correspondente à colheita antecedente a alimentação dos animais, e 2, 4, 6 e 8 horas após o fornecimento da ração aos animais pela manhã.

Para a determinação da uréia utilizou-se o método enzimático colorimétrico ("kit" da linha Bioliquid, Laborclin produtos para Laboratório LTDA, Vargem Grande Pinhais, Paraná, Brasil). 
$\mathrm{O}$ experimento foi conduzido em delineamento experimental em quadrado latino 5 x 5 , com cinco animais, cinco períodos e cinco tratamentos. Adotou-se para análise estatística, o procedimento GLM do programa estatístico SAS (2001). Os dados relacionados à ingestão foram submetidos à análise de regressão conforme o modelo:

$$
\mathrm{Y}_{\mathrm{ijk}}=\mu+\mathrm{A}_{\mathrm{i}}+\mathrm{P}_{\mathrm{j}}+\mathrm{T}_{\mathrm{k}}+\mathrm{e}_{\mathrm{ijk}} \text {, onde: }
$$

$\mathrm{Y}_{\mathrm{ijk}}=$ valor observado; $\mu=$ média geral; $\mathrm{A}_{\mathrm{i}}=$ efeito do animal; $\mathrm{P}_{\mathrm{j}}=$ efeito do período; $\mathrm{T}_{\mathrm{k}}=$ efeito do tratamento e $\mathrm{e}_{\mathrm{ijk}}=$ erro experimental. Os resultados relativos aos parâmetros ruminais e sanguíneos foram realizados em parcelas subdivididas conforme o modelo:
$\mathrm{Y}_{\mathrm{ijk}}=\mu+\mathrm{A}_{\mathrm{i}}+\mathrm{P}_{\mathrm{j}}+\mathrm{T}_{\mathrm{k}}+\mathrm{e}_{\mathrm{ijk}}+\mathrm{H}_{\mathrm{m}}+\mathrm{T}_{\mathrm{k}} \mathrm{xH}_{\mathrm{m}}+\mathrm{e}_{\mathrm{ijkm}}$,

onde:

$\mathrm{Y}_{\mathrm{ijk}}, \mu, \mathrm{A}_{\mathrm{i}}, \mathrm{P}_{\mathrm{j}}, \mathrm{T}_{\mathrm{k}}$, as mesmas variáveis anteriores e $\mathrm{e}_{\mathrm{ijk}}=$ erro da parcela, $\mathrm{H}_{\mathrm{m}}=$ efeito da hora da colheita, $\mathrm{T}_{\mathrm{k}} \times \mathrm{H}_{\mathrm{m}}=$ efeito da interação tratamento e hora da colheita e $\mathrm{e}_{\mathrm{ijkm}}=$ erro experimental.

As diferenças entre as médias foram avaliadas pelo Teste de Tukey a 5\%.

\section{Resultados e Discussão}

Os dados referentes ao consumo de matéria seca (CMS) expresso em $\mathrm{kg}$, em \% do peso vivo $(\mathrm{kg} / \% \mathrm{PV})$, e em gramas por unidade de tamanho metabólico ( $\left.\mathrm{g} / \mathrm{kg} \mathrm{PV}^{0,75}\right)$ e as equações de regressão e os coeficientes de determinação $\left(\mathrm{R}^{2}\right)$ estão apresentados na Tabela 4.

Tabela 4. Consumo médio de matéria seca (CMS) em bovinos de corte alimentados com diferentes níveis de substituição do farelo de algodão pela torta de girassol.

\begin{tabular}{|c|c|c|c|c|c|c|c|}
\hline \multirow[t]{2}{*}{ Consumo } & \multicolumn{5}{|c|}{$\begin{array}{l}\text { Níveis de substituição do farelo de algodão pela torta de } \\
\text { girassol }^{1}\end{array}$} & \multirow[t]{2}{*}{ Regressão } & \multirow[t]{2}{*}{$\mathbf{R}^{2}$} \\
\hline & TG0 & TG25 & TG50 & TG75 & TG100 & & \\
\hline CMS kg & $12,38 \mathrm{a}$ & $11,18 \mathrm{c}$ & $11,74 \mathrm{~b}$ & $11,33 \mathrm{bc}$ & $9,83 \mathrm{~d}$ & $\hat{Y}=12,34-0,083 X+0,002 X^{2}-0,000015 X^{3}$ & 0,28 \\
\hline $\mathrm{g} / \mathrm{kg} \mathrm{PV}^{0,75}$ & $125,80 \mathrm{a}$ & $119,49 \mathrm{ab}$ & $120,41 \mathrm{ab}$ & $112,10 \mathrm{bc}$ & $107,38 \mathrm{c}$ & $\hat{\mathrm{Y}}=2,75-0,0032 \mathrm{X}$ & 0,33 \\
\hline$\% \mathrm{PV}$ & $2,75 \mathrm{a}$ & $2,64 \mathrm{ab}$ & $2,61 \mathrm{~b}$ & $2,56 \mathrm{~b}$ & $2,38 \mathrm{c}$ & $\hat{\mathrm{Y}}=125,89-0,1770 \mathrm{X}$ & 0,20 \\
\hline
\end{tabular}

${ }^{1} 100 \%$ Farelo algodão (TG0); 75\% Farelo algodão + 25\% Torta girassol TG25; 50\% Farelo algodão + 50\% Torta girassol (TG50); 25\% Farelo algodão + 75\% Torta girassol (TG75); 100\% Torta girassol (TG100); Peso vivo (PV) Médias na mesma linha acompanhadas de letras diferentes, diferem entre si $(\mathrm{P} \leq 0,05)$ pelo teste de Tukey.

Houve efeitos significativos $(\mathrm{P} \leq 0,01)$ dos níveis de torta de girassol sobre o consumo de matéria seca (CMS), observando-se comportamento cúbico. No entanto, quando o CMS foi expresso em $\mathrm{g} / \mathrm{kgPV}^{0,75}$ e em \%PV, foi observado comportamento linear decrescente $(\mathrm{P} \leq 0,01)$. Segundo Mertens (1992), citado por Ítavo et al. (2002), diferenças detectadas em diferentes bases de expressão podem estar relacionadas ao teor de fibra e densidade energética da ração. Neste sentido, a melhor base para expressar o consumo, no presente trabalho, foi através do tamanho metabólico (TM), que indicou que quanto maior a substituição do farelo de algodão pela torta de girassol, menor o consumo.

A redução no CMS pelos animais alimentados com rações contendo maiores teores de torta de girassol está de acordo com os resultados encontrados na literatura. Segundo Van Soest (1994), os ácidos graxos insaturados possuem ação tóxica sobre os microrganismos gram-positivos, como as bactérias fribolíticas, o que pode acarretar decréscimo na degradação da fibra presente na dieta. Palmquist e Jenkins (1980) relataram que quando ocorreu 
diminuição na taxa de passagem houve conseqüente redução no CMS. Os ácidos graxos contidos na torta de girassol, que apresentou 24\% de extrato etéreo, segundo Beran et al. (2007), têm a característica de polinsaturados, o que pode induzir a afirmar que estes podem ter levado a redução no consumo conforme aumentou sua substituição em relação ao farelo de algodão. Outra possível justificativa para a redução no CMS seria que o óleo de girassol, rico em ácidos graxos polinsaturados quando biohidrogenados pelas bactérias e protozoários resulta em maior aporte energético (BYERS; SCHELLING, 1993; PETIT et al., 1997), reduzindo, desta maneira, a ingestão de MS.

Os valores de CMS obtidos, no presente estudo, para todas as dietas, foram superiores aos 1,43; 1,54; 1,64; 1,69; e 1,57\% do PV divulgados por Cardoso et al. (2000) trabalhando com novilhos mestiços F1 Limousin $\mathrm{x}$ Nelore, alimentados com feno de capim-coastcross (Cynodon dactylon) e concentrado à base de fubá de milho, farelo de soja, uréia e sal mineralizado. Por outro lado, os consumos médios diários em \% PV estão em consonância com os 2,5\% PV sugeridos pelo NRC (1996) para bovinos de corte.

Os resultados observados, neste trabalho, foram ligeiramente inferiores aos 2,87; 3,11; 3,12; e $2,62 \% \mathrm{PV}$ divulgados por Ítavo et al. (2002) que estudaram o CMS em novilhos nelore, arraçoados com quatro níveis de concentrados $(20 ; 40 ; 60$ e $80 \%$ ) na ração, respectivamente, com base na MS, usando feno de capim-Tifton 85 como volumoso. Estes autores sugeriram que animais na fase de crescimento $(165 \mathrm{~kg})$ apresentam maior capacidade de CMS em \% PV e em $\mathrm{g} / \mathrm{kg}$ de $\mathrm{PV}^{0,75}$ do que animais na fase de terminação.

Pode-se observar que não houve efeito dos tratamentos $(\mathrm{P}>0,05)$ sobre os valores de $\mathrm{pH}$ segundo os tempos de colheitas (Tabela 5).

Os valores de $\mathrm{pH}$ do líquido ruminal de bovinos do TG0 apresentaram valores mais baixos no decorrer das colheitas, embora esta diferença não seja significativa em relação aos outros tratamentos.

Tabela 5. pH do líquido ruminal de bovinos de corte alimentados com diferentes níveis de substituição do farelo de algodão pela torta de girassol, em função do tempo após alimentação.

\begin{tabular}{lccccc}
\hline \multirow{2}{*}{ Horas } & \multicolumn{5}{c}{ Níveis de substituição do farelo de algodão pela torta de girassol } \\
\cline { 2 - 6 } & TG0 & TG25 & TG50 & TG75 & TG100 \\
\hline 0 & 6,56 & 6,71 & 6,87 & 6,93 & 6,92 \\
2 & 6,17 & 6,34 & 6,49 & 6,41 & 6,51 \\
4 & 6,00 & 6,11 & 6,32 & 6,35 & 6,30 \\
6 & 5,98 & 6,23 & 6,37 & 6,26 & 6,29 \\
8 & 6,19 & 6,43 & 6,52 & 6,56 & 6,54 \\
\hline
\end{tabular}

${ }^{1} 100 \%$ Farelo algodão (TG0); 75\% Farelo algodão + 25\% Torta girassol (TG25); 50\% Farelo algodão + 50\% Torta girassol (TG50); $25 \%$ Farelo algodão + 75\% Torta girassol (TG75); 100\% Torta girassol (TG100).

O líquido ruminal apresentou menor $(\mathrm{P}>0,05)$ valor de $\mathrm{pH}(5,98)$ com seis horas pós-prandial. Esta diminuição do $\mathrm{pH}$ está relacionada com o pico de produção de ácidos graxos voláteis no rúmen. Todos os tratamentos apresentaram uma curva que mostra que o $\mathrm{pH}$ mais baixo está entre quatro e seis horas após fornecimento da ração.
Os valores de $\mathrm{pH}$ mais elevados, apesar de não serem diferentes, foram encontrados no líquido ruminal de animais alimentados com rações contendo níveis mais elevados de torta de girassol (TG50; TG75; e TG100) em substituição ao farelo de algodão na ração, podendo ser decorrentes do menor consumo de MS diário. Em conseqüência da redução 
do consumo, pode ter havido redução da fermentação microbiana ruminal, e consequentemente, queda na produção de ácidos graxos voláteis, que poderia justificar o $\mathrm{pH}$ mais alto para estes tratamentos.

Os valores de $\mathrm{pH}$ ruminal variaram de 5,98 (TG0) a 6,93 (TG75), os quais foram relativamente baixos quando comparados aos valores de 7,03; 6,94; 6,65 e 6,33 relatados por Carvalho et al. (1997) determinados em bovinos alimentados com rações completas compostas com 80;67,5; 55; 42,50 e 30 de concentrados e feno de capim-elefante, nos tempos de colheitas de $0 ; 2 ; 4$; e 6 horas após alimentação, respectivamente. Entretanto, quando se comparou o valor de $\mathrm{pH}$ de 6,65 obtidos por esses autores ao usarem dietas com $55 \%$ de concentrado, verifica-se que foi muito semelhante à média obtida no presente estudo.

Oliveira Júnior (2002), trabalhando com uréia ou amiréia em substituição ao farelo de soja, 80\% de concentrado com base na MS e dietas isoprotéicas (13\%) na alimentação de bovinos de corte, mantendo o bagaço de cana-de-açúcar in natura como volumoso, obteve valores de $\mathrm{pH}$ no fluido ruminal entre 6,42 a 6,71 , valores, estes, próximos aos determinados neste trabalho. No entanto, Carmo (2001), estudando a inclusão de uréia em 2\% na MS da ração, em substituição parcial ao farelo de soja e amiréia como fontes protéicas, em dietas para vacas leiteiras com $55 \%$ de concentrado, obteve valores de $\mathrm{pH}$ mais baixos, entre 5,62 a 6,45. Porém, podese deduzir que não houve comprometimento na digestão ruminal da fibra, pois segundo Orskov (1988) e Hoover(1986), a digestão é prejudicada com pH inferior a 6,2. Neste sentido, apenas as amostras de TG0 e TG25 apresentaram valores inferiores aos sugeridos por estes autores, porém, próximos ao mínimo sugerido para não haver redução na digestão da fibra e dentro da faixa preconizada para o máximo crescimento microbiano, que devem estar entre 5,5 e 7,0 (COELHO DA SILVA; LEÃO,1979; ORSKOV,1988; HOOVER; STOKES, 1991).
Não houve diferença significativa de $\mathrm{N}^{-\mathrm{NH}_{3}}$ no fluido ruminal entre os cinco tratamentos. As concentrações de $\mathrm{N}_{-} \mathrm{NH}_{3}$ foram influenciadas pelos tempos de coletas, após o fornecimento das rações, independente do tratamento. Estes valores sugerem que todos os tratamentos estudados influenciaram da mesma maneira os valores de $\mathrm{N}_{-} \mathrm{NH}_{3}$ em relação aos tempos de colheitas de líquido ruminal.

As concentrações médias de $\mathrm{N}-\mathrm{NH}_{3}$, no líquido ruminal, para todas as rações estiveram acima do mínimo requerido para o máximo crescimento microbiano e de digestão ruminal que, de acordo com NRC (1984) é de $5 \mathrm{mg} / \mathrm{dL}$.

Neste sentido, Beran (2007) estudando coderivados de girassol, verificou valores superiores na degradabilidade efetiva da proteína bruta, a uma taxa de passagem de $5 \% / \mathrm{h}$, de 94,48 e $95,93 \%$ para torta de girassol com uma e duas passagens pela prensa e $80,79 \%$ para o farelo de algodão. Corroborando com estes dados, pode-se verificar, na Tabela 3, que houve acréscimo na PDR dos tratamentos com os aumentos nos níveis de substituição da torta de girassol em relação ao farelo de algodão. Porém, na Tabela 4, pode-se observar que houve decréscimo no CMS proporcional aos níveis crescente de substituição do farelo de algodão pela torta de girassol, ocasionando com isto, teores de $\mathrm{N}_{-} \mathrm{NH}_{3}$ semelhantes entre os tratamentos.

Os dados obtidos no presente estudo estão contidos na faixa de 3,1 a $14,5 \mathrm{mg}$ de $\mathrm{N}-\mathrm{NH}_{3} / \mathrm{dL}$ de líquido ruminal, semelhantes aos obtidos por Zeoula et al. (2002) ao alimentar novilhos da raça holandesa com rações contendo diferentes fontes de amido e de nitrogênio. Entretanto, foram inferiores a 11,8 a $17,9 \mathrm{mg} / \mathrm{dL}$, relatados por Oliveira Júnior (2002), que trabalharam com $80 \%$ de concentrado na ração de bovinos de corte. Desta maneira, os resultados obtidos neste trabalho induzem a afirmar que a torta de girassol é um suplemento protéico que pode ser usado na alimentação de bovinos, pois fornece teores de nitrogênio em quantidades para o bom desenvolvimento das bactérias no rúmen. 
Tabela 6. Concentração de nitrogênio amoniacal ( $\left.\mathrm{N}^{-\mathrm{NH}_{3}} \mathrm{mg} / \mathrm{dL}\right)$ no fluido ruminal de bovinos de corte alimentados com diferentes níveis de substituição do farelo de algodão pela torta de girassol, em função do tempo após alimentação.

\begin{tabular}{lccccc}
\hline \multirow{2}{*}{ Horas } & \multicolumn{5}{c}{ Níveis de substituição do farelo de algodão pela torta de girassol' } \\
\cline { 2 - 6 } & TG0 & TG25 & TG50 & TG75 & TG100 \\
\hline 0 & 5,45 & 5,54 & 5,60 & 5,72 & 5,62 \\
2 & 10,12 & 10,53 & 10,16 & 10,21 & 10,11 \\
4 & 9,05 & 9,28 & 8,85 & 8,55 & 8,45 \\
6 & 8,27 & 8,02 & 8,11 & 7,34 & 7,34 \\
8 & 6,80 & 6,82 & 6,72 & 6,12 & 6,02 \\
\hline
\end{tabular}

${ }^{1} 100 \%$ Farelo algodão (TG0); $75 \%$ Farelo algodão $+25 \%$ Torta girassol TG25; 50\% Farelo algodão $+50 \%$ Torta girassol (TG50); $25 \%$ Farelo algodão $+75 \%$ Torta girassol (TG75); $100 \%$ Torta girassol (TG100).

Os cinco tratamentos estudados apresentaram maior concentração de $\mathrm{N}-\mathrm{NH}_{3}$ aproximadamente 2 horas após o fornecimento das rações. Estes resultados são semelhantes aos verificados por Oliveira Júnior et al. (2004) e por Sampaio, Vieira e Brito (2000), que trabalharam com bovinos da raça Gir alimentados com farelo de algodão e levedura, e volumoso na proporção de $60 \%$, com base na MS, e encontraram picos na concentração de $\mathrm{N}_{-} \mathrm{NH}_{3}$ nas duas primeiras horas, com valores de 8,31 e 8,86 mg de $\mathrm{N}-\mathrm{NH}_{3} / \mathrm{dL}$ de líquido ruminal, respectivamente.

Pode-se observar na Tabela 7 que não houve diferença significativa entre os valores médios de uréia plasmática entre os cinco tratamentos. Os valores médios de uréia plasmática variaram no decorrer das colheitas, sendo observado pico máximo às duas horas após alimentação.

Tabela 7. Concentração de uréia plasmática de bovinos de corte alimentados com diferentes níveis de substituição do farelo de algodão pela torta de girassol, em função do tempo após alimentação.

\begin{tabular}{cccccc}
\hline \multirow{2}{*}{ Horas } & \multicolumn{5}{c}{ Níveis de substituição do farelo de algodão pela torta de girassol } \\
\cline { 2 - 5 } & TG0 & TG25 & TG50 & TG75 & TG100 \\
\hline 0 & 8,79 & 8,85 & 8,86 & 8,86 & 8,83 \\
2 & 13,80 & 13,59 & 13,78 & 13,46 & 13,59 \\
4 & 13,33 & 13,22 & 13,34 & 13,29 & 13,23 \\
6 & 10,71 & 10,86 & 10,91 & 11.01 & 10,61 \\
8 & 9,45 & 9,46 & 9,65 & 9,60 & 9,45 \\
\hline
\end{tabular}

${ }^{1} 100 \%$ Farelo algodão (TG0); 75\% Farelo algodão + 25\% Torta girassol TG25; 50\% Farelo algodão + 50\% Torta girassol (TG50); 25\% Farelo algodão + 75\% Torta girassol (TG75); 100\% Torta girassol (TG100).

Foi observado pico máximo de uréia plasmática nas colheitas realizadas $2 \mathrm{~h}$ após a alimentação. Este fato é explicado pelo pico de $\mathrm{N}_{-} \mathrm{NH}_{3}$ no rúmen também ter ocorrido após $2 \mathrm{~h}$ da alimentação. Sabese que a uréia é sintetizada no fígado a partir de $\mathrm{N}-\mathrm{NH}_{3}$ proveniente do catabolismo das proteínas e pela absorção através da parede ruminal e metabolização, transforma-se em uréia (FORBES; FRANCE, 1993; ROCHA, 2002). Este processo leva o animal a gastar energia para metabolizar o $\mathrm{N}-\mathrm{NH}_{3}$ em uréia, a fim de evitar a sua toxicidade (SWENSON; REECE, 1996).

Oliveira Júnior (2002) observou o pico de uréia plasmática entre 4 e 6 h. No presente experimento, 
foram obtidos menores valores, justificando o decréscimo mais rápido da curva de uréia, pois o excedente de $\mathrm{N}-\mathrm{NH}_{3}$ metabolizado foi relativamente baixo.

Os valores determinados no presente trabalho estão abaixo dos obtidos por Valadares et al. (1997), que fornecendo uma ração com 12\% de PB para novilhos zebus obtiveram valores em torno de $17 \mathrm{mg} / \mathrm{dL}$. Porém, estão acima dos valores de 8,6 $\mathrm{mg} / \mathrm{dL}$ verificado por Thomson, Preston e Bartle (1995), para animais alimentados com rações com $13 \%$ PB.

Em todas as colheitas, as concentrações de uréia plasmática estão abaixo dos limites a partir dos quais estariam ocorrendo perdas de $\mathrm{N}$ dietético em vacas leiteiras, que segundo Oliveira, Valadares e Valadares (2001) é acima de 24 a $25 \mathrm{mg} / \mathrm{dL}$ de sangue.

Oliveira, Valadares e Valadares (2001) trabalharam com níveis crescentes de nitrogênionão-protéico (NNP) na ração de bovinos de corte e verificaram comportamento linear crescente em função do aumento destes níveis. Apesar da forma nitrogenada ser diferente, mas considerando o fator solubilidade protéica da proteína da torta de girassol, os resultados obtidos neste estudo são condizentes aos divulgados por Rennó et al. (2000), que concluíram que a concentração plasmática de uréia aumentou linearmente com as porcentagens de PB com valores variáveis.

Os valores encontrados no presente experimento estão próximos aos determinados por Carmo (2001), que testou farelo de soja como principal fonte protéica e proporção de concentrado:volumoso de 55:45\% e encontrou valores plasmáticos de uréia entre 16,87 e $19,87 \mathrm{mg} / \mathrm{dL}$.

\section{Conclusões}

Pode-se concluir que a torta de girassol pode substituir até $75 \%$ do farelo de algodão nas rações de bovinos de corte.
Níveis superiores a $75 \%$ de girassol em substituição ao farelo de algodão podem reduzir a ingestão de matéria seca em bovinos de corte, porém não alteram os valores de $\mathrm{pH}$ e de $\mathrm{N}-\mathrm{NH}_{3}$ no líquido ruminal e na uréia plasmática.

\section{Referências}

ASSIS, A. J.; CAMPOS, J. M. S.; QUEIROZ, A. C.; VALADARES FILHO, S. C.; EUCLYDES, R. F.; LANA, R. de P.; MAGALHÃES, A. L. R.; MENDES NETO, J.; MENDONÇA, S.de S. Polpa cítrica em dietas de vacas em lactação. 2. Digestibilidade dos nutrientes em dois períodos de coleta de fezes, $\mathrm{pH}$ e nitrogênio amoniacal do líquido ruminal. Revista Brasileira de Zootecnia, Viçosa, MG, v. 33, n. 1, p. 251-257, 2004.

BERAN, F. H. B.; SILVA, L. D. F.; RIBEIRO, E. L. A.; ROCHA, M. A.; EZEQUIEL, J. M. B.; CORREA, R. A.; CASTRO, V. S.; SILVA, K. C. F. Avaliação da digestibilidade de nutrientes, em bovinos, de alguns alimentos concentrados pela técnica de três estádios. Revista Brasileira de Zootecnia, Viçosa, MG, v. 36, n. 5, p. 130-137, 2007.

BYERS, F. M.; SCHELLING, G. T. Los lipidos en la nutrción de los rumiantes. In: CHURCH, C. D. (Ed.). El rumiante: fisiologia y nutrición. Zaragoza: Acribia, 1993. p. 339-356.

CARDOSO, R. C.; VALADARES FILHO, S. C.; SILVA, J. F. C.; PAULINO, M. F.; VALADARES, R. F. D.; CECON, P. R.; COSTA, M. A. L.; OLIVEIRA, R. V. de. Consumo e digestibilidades aparentes totais e parciais de rações contendo diferentes níveis de concentrado, em novilhos F1 Limousin X Nelore. Revista Brasileira de Zootecnia, Viçosa, MG, v. 29, n. 6, p. 1832-1843, 2000.

CARMO, C. A. Substituição do farelo de soja por uréia ou amiréia em dietas para vacas leiteiras em final de lactação. Piracicaba: ESALQ, 2001. Dissertação (Mestrado em Agronomia) - Departamento de Agronomia. Escola Superior de Agricultura Luiz de Queiroz, Piracicaba.

CARVALHO, A. U.; VALADARES FILHO, S .C.; COELHODASILVA, J.F.; CECON, P. R.; VALADARES, R. F. D.; GOUVEIA, R. C. C. O. Níveis de concentrado em dietas de zebuínos. 4. Concentrações ruminais de amônia e $\mathrm{pH}$, taxa de passagem da digesta ruminal e degradação in situ dos alimentos. Revista Brasileira de Zootecnia, Viçosa, MG, v. 26, n. 5, p. 1016-1024, 1997. 
COELHO DA SILVA, J. F.; LEÃO, M. I. Fundamentos de nutrição dos ruminantes. Piracicaba: Livroceres, 1979. $380 \mathrm{p}$.

FORBES, J. M.; FRANCE, J. Quantitative aspects of ruminat digestion and metabolism. Wallingford: $\mathrm{CAB}$ International, 1993, $515 \mathrm{p}$.

HOOVER, W. H. Chemical factores involved in ruminal fiber digestion. Journal of Dairy Sciences, v. 69, n. 10, p. 2755-2766, 1986.

HOOVER, W. H.; TOKES, S. R. Balancing carbohydrates and proteins for optimum rumen microbial yield. Journal of Dairy Sciences, v. 74, n. 10, p. 3630-3644, 1991.

ÍTAVO, L. C. V.; VALADARES FILHO, S. C.; SILVA, F. F.; VALADARES, R. F. D.; CECON, P. R.; FERREIRA, C. C. B.; ÍTAVO, C. C. B. F.; MORAES, E. H. B. K.; PAULINO, P. V. R. P. Níveis de concentrado e proteína bruta na dieta de bovinos nelore nas fases de recria e terminação: consumo e digestibilidade. Revista Brasileira de Zootecnia, Viçosa, MG, v. 31, n. 3, p. 1553-1561, 2002. Suplemento.

KOZLOSKI, G. V. Bioquímica dos ruminantes. Santa Maria: Ed. UFSM, 2002, 140 p.

McDOWELL, L. R.; CONRAD, J. H.; THOMAS, J. E.; HARRIS, L. E. Tabelas de composição de alimentos da América Latina. Gainesville: Universidade de Flórida, 1974, 63 p.

NATIONAL RESEARCH COUNCIL - NRC. Nutrients requirements of beef cattle. 7 ed. Washington D.C.: National Academic Press, 1996, 242 p.

.Nutrients requirements of beef cattle. Washington D.C.: National Academic Press, 1984, 90 p.

OLIVEIRA JUNIOR, R. C. Substituição do farelo de soja por uréia ou amiréia em dietas de bovinos de corte. 1 digestibilidade dos nutrientes, balanço de nitrogênio, parâmetros ruminais e sanguíneos. 2 desempenho. 3 avaliação de indicadores de digestibilidade. Piracicaba: ESALQ, 2002. Tese (Doutorado em Agronomia) Departamento de Agronomia. Escola Superior de Agricultura Luiz de Queiroz, Piracicaba.

OLIVEIRAJUNIOR, R. C.; PIRES, A. V.; FERNANDES, J. J. R.; SUSIN, I.; SANTOS, F. A. P.; ARAÚJO, R. C. Substituição total do farelo de soja por uréia ou amiréia, em dietas com alto teor de concentrado, sobre a amônia ruminal, os parâmetros sanguíneos e o metabolismo do nitrogênio em bovinos de corte. Revista Brasileira de Zootecnia, Viçosa, MG, v. 33, n. 3, p. 738-748, 2004.
OLIVEIRA,A.S.;VALADARES, R.F.D.;VALADARES FILHO, S. C. Produção de proteína microbiana e estimativas das excreções de derivados de purinas e de uréia em vacas lactantes alimentadas com rações isoprotéicas contendo diferentes níveis de compostos nitrogenados não-protéicos. Revista Brasileira de Zootecnia, Viçosa, MG, v. 30, n. 5, p. 1621-1629, 2001.

ORSKOV, E. R. Nutrición protéica de los ruminantes. Zaragoga: Acribia, 1988. 157 p.

PALMQUIST, D. L.; JENKINS, T. C. Fat in lactation rations: review. Journal of Dairy Sciences, local, v. 63, n. 1, p. 1-14, 1980.

PETIT, H. V.; RIOUX, R.; D’OLIVEIRA, P. S.; PRADO, I. N. do. Performance of growing lambs fed silage with raw or extruded soybean or canola seeds. Canadian Journal of Animal Sciences, Ottawa, v. 77, n. 3, p. 455463, 1997.

RENNÓ, N. L.; VALADARES, R. F. D.; VALADARES FILHO, S. C.; LEÃO, M. I.; SILVA, J. F. C. da; CECON, P. R.; GONÇALVES, L. C.; DIAS, H. L. C.; LINHARES, R. S. Concentração plasmática de uréia e excreção de uréia e creatinina em novilhos. Revista Brasileira de Zootecnia, Viçosa, MG, v. 29, n. 4, p. 1235-1243, 2000.

ROCHA, M. H. M. Teores de proteina bruta em dietas com alta proporção de concentrado para cordeiros confinados. Piracicaba, SP: ESALQ, 2002. Dissertação (Mestrado em Agronomia) - Departamento de Agronomia. Escola Superior de Agricultura Luiz de Queiroz, Piracicaba.

SAMPAIO, A. A. M.; VIEIRA, P. F.; BRITO, R. M. Produção de amônia na fermentação in vitro de rações com levedura, uréia ou farelo de algodão. Revista Brasileira de Zootecnia, Viçosa, MG, v. 29, n. 2, p. 598602, 2000.

SAS Institute. SAS/STAT User's guide. Version 8.2, 6. ed. Cary: Statistical Analysis System Institute, NC, USA, 2001.

SILVA, D. J.; QUEIROZ, A. C. Análises de alimentos: métodos químicos e biológicos. 3. ed. Viçosa, MG: UFV, 2002, $235 \mathrm{p}$.

SWENSON, M. J.; REECE, W. O. Dukes fisiologia dos animais. 11. ed. Rio de Janeiro: Guanabara Koogan, 1996, $856 \mathrm{p}$.

THOMSON, D. U.; PRESTON, R. L.; BARTLE, S. J. Influence of protein source and level on the performance, plasma urea nitrogen and carcass characteristics of finishing beef steers. Journal of Animal Sciences, Philadelphia, v. 73, p. 257, 1995. Suplemento 1. 
VALADARES， R. F. D.; GONÇALVES， L. C.; RODRIGUEZ, N. M.; VALADARES FILHO, S. C.; SAMPAIO, I. B. Níveis de proteína em dietas de bovinos. 4. concentração de amônia ruminal e uréia plasmática e excreções de uréia e creatinina. Revista Brasileira de Zootecnia, Viçosa, MG, v. 26, n. 6, p. 1270-1278, 1997.

Van SOEST, P. J. Nutritional ecology of the ruminant. 2. ed. Ithaca: Cornell University Press, 1994.
VIEIRA, P. F. Efeito do formaldeído na proteção de proteínas e lipídios em rações para ruminantes. Viçosa MG; UFV, 1980. Tese (Doutorado em Zootecnia) Departamento de Zootecnia. Universidade Federal de Viçosa, Viçosa.

ZEOULA, L. M.; CALDAS NETO, S. F.; BRANCO, A. F.; PRADO, I. N.; DALPONTE, A. O.; KASSIES, M.; FREGADOLLI, F. L. Mandioca e resíduos das farinheiras na alimentação de ruminantes: $\mathrm{pH}$, concentração de N-NH3 e eficiência microbiana. Revista Brasileira de Zootecnia, Viçosa, MG, v. 30, n. 3, p. 1582-1593, 2002. Suplemento. 
